\title{
INDIOS NATURALES Y FLORIDANOS EN GUANABACOA, LA HABANA, CUBA
}

\section{Natural and Floridian Indians in Guanabacoa, Havana, Cuba}

\section{Lisette Roura Álvarez}

Arqueóloga, Doctora en Ciencias Históricas, Gabinete

de Arqueología de la Oficina del Historiador de La

Habana, Universidad de La Habana.

Correo-e: roura@patrimonio.ohc.cu

ORCID: 0000-0003-0323-9116

\section{Odlanyer Hernández de Lara}

Arqueólogo, Licenciado en Antropología, Archaeolo-

gical and Historical Conservancy, Inc.

Correo-e: hernandezdelara@gmail.com

ORCID: 000-0001-5777-0338

Recibido: 22/10/2019 • Aprobado: 7/11/2019

Cómo citar: Roura Álvarez, L., \& Hernández de Lara, O. (2019). Indios naturales y floridanos en Guanabacoa, La Habana, Cuba. Ciencia y Sociedad, 44(4), 35-50. https://doi.org/10.22206/cys.2019.v44i4.pp35-50

\section{Resumen}

La relevancia histórica de Guanabacoa, poblado que surge como reducción de indios en La Habana y donde se sucedieron importantes procesos sociohistóricos, contrasta con la exigüidad de intervenciones arqueológicas practicadas, y la necesidad de dilucidar cuestiones relativas al emplazamiento de la primera iglesia y cementerio, área que constituyó el núcleo urbano a partir del cual se expandió y conformó el actual municipio. En función de esto se implementó el proyecto arqueológico Indios naturales $y$ floridanos en Guanabacoa con el propósito de constatar la ubicación de las mencionadas estructuras, enfocado además en la presencia e interacción de indios naturales y floridanos. El análisis de las abundantes y significativas evidencias arqueológicas halladas constata la continuidad de algunas producciones tradicionales aruacas y la presencia de indios floridanos en el entorno urbano guanabacoense del siglo XviII. Igualmente, ilustran sobre el comercio, la producción de azúcar, la religión, el divertimento, la construcción de inmuebles, la alimentación, el procesamiento de alimentos y actividades que incluían elementos vinculados con la apariencia personal. Los resultados obtenidos en la primera etapa de investigación arqueológica evidencian la necesidad de continuar la implementación del proyecto en el área seleccionada.

Palabras claves: indios; La Habana; Guanabacoa; La Florida; artefactos.

\begin{abstract}
The historical relevance of Guanabacoa, a town that emerged as a result of the forcible relocation of the Indians and where significant socio-historic processes occurred, is in sharp contrast to the lack of archaeological attention it has received and the need to determine the location of the first church and the cemetery. This area was the core of the village which was subsequently expanded and eventually became the current municipality. To answer these questions, a new archaeological project, Indios naturales $y$ floridanos en Guanabacoa (Natural and Florida Indians in Guanabacoa) is underway to determine the location of the aforementioned structures, focusing on the presence and interaction between natural and Florida Indians. The analysis of significant and abundant archaeological finds demonstrates the continuity of some traditional Arawak artifacts and the emergence of Florida Indian artifacts within the urban core of Guanabacoa during the 18thcentury. Likewise, these finds provide insights about trade, sugar production, religion, games, construction of buildings, food, foodways, and personal grooming. The results of the first archaeological fieldwork show the need for more in-depth research within the selected area.
\end{abstract}

Keywords: Indians; Havana; Guanabacoa; Florida; artifacts. 
Las investigaciones arqueológicas efectuadas en lo que hoy se reconoce como Centro Histórico La Habana Vieja han demostrado que la materialidad artefactual de antaño no se circunscribía a segmentos territoriales, pues los intercambios comerciales y las migraciones dinamizaron y complejizaron las relaciones sociales, identificables en los depósitos estudiados. Por lo tanto, no pueden entenderse los procesos sociohistóricos acaecidos en la región habanera si se obvian zonas tan antiguas y de gran significación como Guanabacoa.

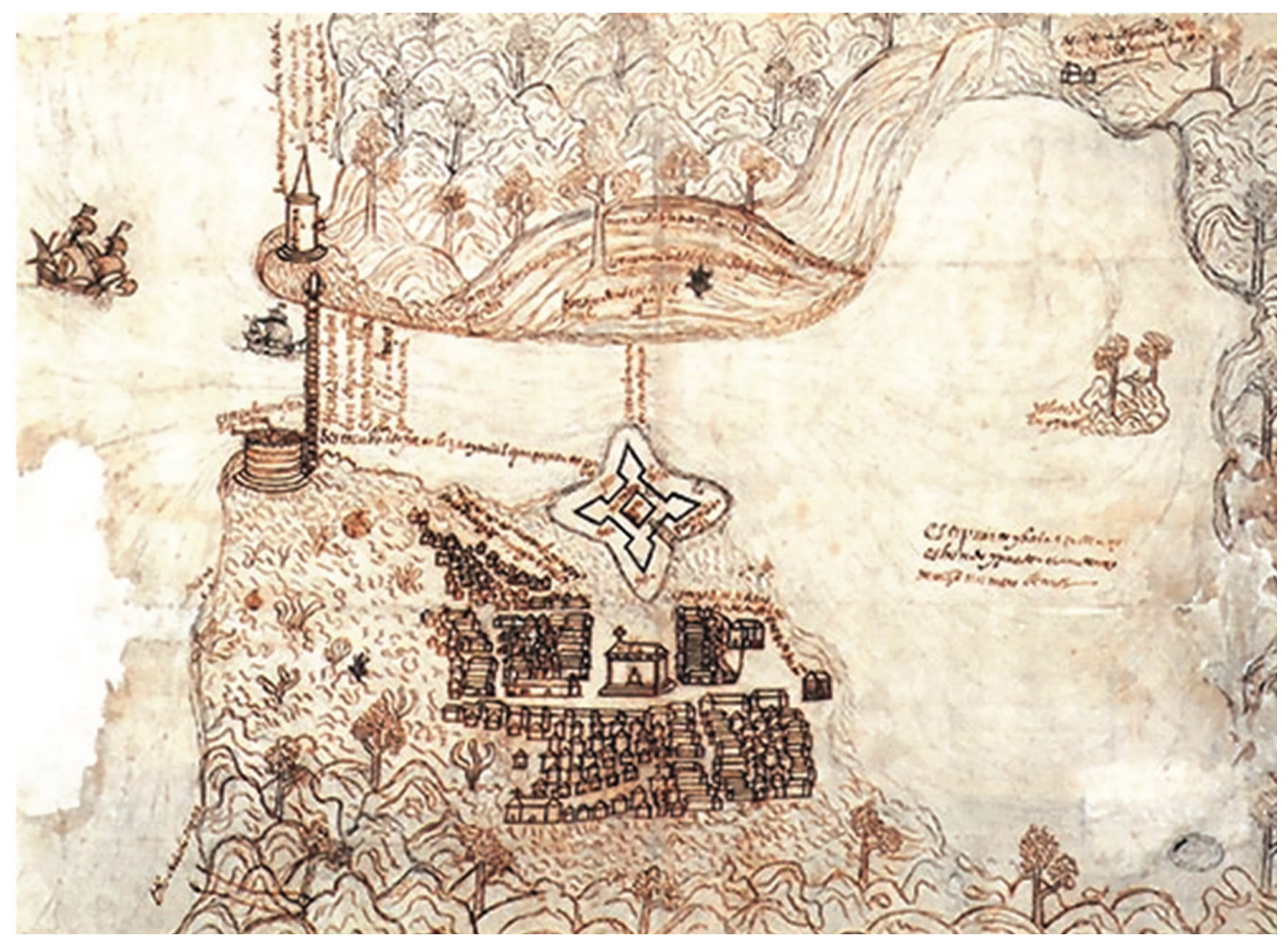

Figura 1. Imagen de la región habanera donde puede leerse en la parte superior derecha: "Aquí está el pueblo de los indios de Guanabacoa”.

Fuente: Plano de La Habana en perspectiva, 1567, anónimo. Archivo General de Indias

Estudios recientes (Rodríguez, 2002; Roura, 2014; Roura, Arrazcaeta, y Hernández, 2017; Roura, 2018) advierten la presencia de descendencia biológica indígena en territorio guanabacoense, hasta al menos la primera mitad del siglo xviII, y la producción cerámica que esta mantuvo como elemento comercializable. Las huellas de estas transacciones pueden identificarse en artefactos exhumados en La Habana Vieja, utilizando para su fabricación afloramientos de arcillas ubicados en el antiguo y extenso territorio guanabacoense. Pero en este también se asentaron indios procedentes de diversas 
regiones americanas, entre los que se destacan, por su número, los que arribaron desde tierras floridanas. Es conocido el intenso trasiego de personas e intercambio de mercancías entre La Florida y La Habana a partir del siglo xvI, y aunque evidencias arqueológicas halladas en varias zonas habaneras lo confirman, no se han efectuado intervenciones sistemáticas en áreas guanabacoenses que permitan ahondar en tan significativa cuestión.

Al tomar como punto de partida lo anterior, en el año 2019 comienza a ejecutarse el proyecto Indios naturales y floridanos en Guanabacoa, liderado por especialistas del Gabinete de Arqueología de la Oficina del Historiador de La Habana, con la colaboración de Archaeological and Historical Conservancy, Inc., organización no gubernamental y sin fines de lucro dedicada a la investigación y preservación de sitios históricos y arqueológicos de La Florida y El Caribe. El desarrollo de este proyecto se enfoca en el estudio del área donde estuvo ubicada la primera iglesia y cementerio de la localidad en el siglo Xvi. Aun cuando la información histórica sugiere que las citadas estructuras se situaban en dicho entorno, no existe constancia arqueológica de su disposición exacta.

Las características inherentes a la geografía de Guanabacoa (con elevaciones reiteradas, principalmente en la zona urbana), los escasos espacios disponibles para situar excavaciones arqueológicas y los incontables cambios acaecidos a nivel de subsuelo por casi cinco siglos, han influido en las exiguas intervenciones arqueológicas y en la profundización sobre la trascendencia histórica de la fundación de Guanabacoa como reserva india. Mediante la localización e intervención de la antigua área sepulcral (dentro y fuera del primer templo) y el estudio del ajuar artefactual asociado a los enterramientos, se pretende profundizar en las relevantes relaciones comerciales y vecinales establecidas entre los indios naturales y los procedentes de La Florida, en la importancia de estos factores en la conformación del etnos en la región habanera, y en la evolución del poblado-villa-municipio mediante la expansión urbana, tomando como punto de partida la ubicación de la primera iglesia y cementerio. Los resultados pretenden aportar elementos vinculados con la historia local y regional, incentivar las investigaciones relacionadas con el tema y promover exposiciones transitorias y/o permanentes, posibilitando efectivizar la relación investigación arqueológica-comunidad.

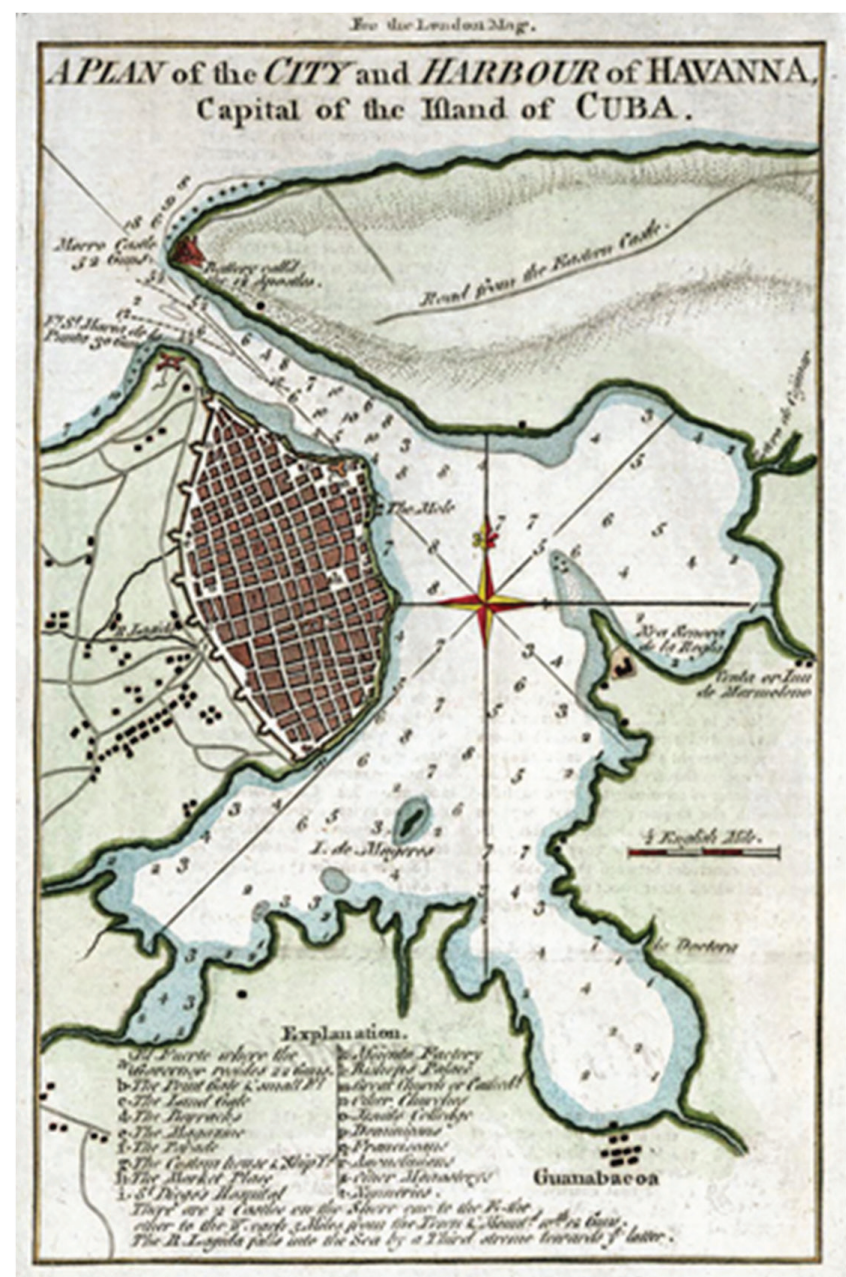

Figura 2. Ubicación de Guanabacoa con respecto al núcleo poblacional de La Habana.

Fuente: A Plan of the City and Harbour of Havanna, Capital of the Island of Cuba - The London magazine, or, Gentleman's monthly intelligencer (1762). 


\section{Indios naturales y floridanos: referentes históricos}

Guanabacoa constituía una población que pertenecía a la jurisdicción de La Habana, y no fue hasta el año 1649 que "(...) tendría su propio Cabildo, Justicia y Regimiento" (Rodríguez, Martínez, González, Soroa, y Roque, 2006, p. 45), alcanzando en 1743 el título de Villa Nuestra Señora de la Asunción. Se fundó en 1554 como pueblo de indios al este del núcleo urbano habanero, en un entorno natural donde se combinaban llanuras extensas y pequeñas elevaciones. Una de las más antiguas referencias a este poblado se encuentra con motivo del asalto del pirata francés Jacques de Sores a La Habana en 1555, cuando “(...) se reúnen el gobernador y los señores capitulares en consulta y cabildo en el pueblo de indios de Guanabacoa término y jurisdicción de la villa de la Habana" (Roig, 1963, p. 34). En las relaciones enviadas por el cabildo habanero al rey de España sobre dicho asalto se menciona la existencia de un pueblo de indios que estaba a una legua de La Habana, donde había cien indios, aunque casi todos estaban en el monte (Roig, 1963, p. 34). Gonzalo Pérez de Angulo, gobernador de Cuba entre los ańos 1550 y 1556, intentó reunir hombres para sorprender a los piratas que habían tomado La Habana y convocó a los indios que andaban dispersos en las afueras de la población; logró reunir noventa y cinco espańoles, doscientos veinte negros y ochenta naturales armados con piedras y palos (Wright, 1927, p. 28). Otras fuentes citan que el gobernador logró reunir a más de treinta españoles, unos cien negros y alrededor de cien indígenas (Colección de Documentos Inéditos, 2a serie, tomo VI, pp. 366-368; en Rodríguez et al., 2006, p. 28).

El obispo Bernardino de Villalpando, tras visitar la Isla, redactaba el informe correspondiente para uso de la corte (desde Santiago de Cuba el 14 de abril de 1563), en el que señalaba la existencia de tres pueblos de indios en Cuba: Baracoa, Guanabacoa y Trinidad. Al segundo se refería como inmediato a la capital, y lo registra como “(...) pueblo en que ay solo yndios y los desta tierra son tan pobres que no pueden mantener sacerdote (...) porque (...) no abia ninguno allí que quisise ir a dezir misa sino era con esperanza de ganar alguna cosa (...)" (Hernández, 2011, p. 3). Posteriormente se reporta que "(...) al otro lado de la bahía en 1570 había sesenta indios casados" (Portuondo, 1965, p. 130).

En 1574 se dictaron las Ordenanzas para el buen gobierno de la ciudad de San Cristóbal de La Habana $y$ de todos los pueblos de la Isla, conformadas por Alonso de Cáceres y presentadas por primera vez al cabildo habanero el 15 de enero de 1574 (Roig, 1963 , p. 86). Dicha acta constituye un documento de gran importancia, pues referenciaba a Guanabacoa como un pueblo donde habitaban más de trescientos indios. ${ }^{1}$ Con el aumento de la población, la descendencia indígena se vio obligada a acudir a los capitulares mediante su protector, según consta el 7 de abril del mismo año; desde ese día se acordó concederle un sitio de cuatro leguas a la redonda "(...) por la necesidad que tienen dichos indios". ${ }^{2}$ En 1582 se reportaban cuarenta y seis indios naturales hombres, incluyendo su capitán Diego Martín, y once españoles ${ }^{3}$ como habitantes del poblado. Cuando las autoridades intentaron agrupar a todos los indios que se hallaban dispersos en las afueras del núcleo urbano ultramarino, las consecuencias fueron desfavorables. Dio por resultado la insuficiencia de esclavos negros que sustituyeran a los naturales en los campos, los rebaños de ganado se dispersaron, y disminuyó el abastecimiento de carne en La Habana. Se acordó entonces permitírseles la continuidad de sus labores mediante un salario concertado previamente ante el protector de los indios (Venegas, 2012, p. 73).

1. Actas Capitulares del Ayuntamiento de La Habana trasuntadas 1566-1574. (1939), Vol. II, p. 25.

2. Ídem.

3. Lista y memoria de los vezinos y moradores desta villa de la havana y del pueblo de guanavacoa (Wright, 1927, p. 313). 
En el año 1605 se redacta una interesante relación de habitantes de Guanabacoa:

Tabla 1. Habitantes de Guanabacoa en el año 1605. Núñez, C. 1845. Noticias históricas de la Villa de la Asunción de Guanabacoa.

\begin{tabular}{l|c}
\hline Procedencia/color de la piel & No. de individuos \\
\hline Indios & 36 \\
Naturales & 84 \\
Espańoles & 31 \\
Floridanos & 4 \\
Maracaibo & 1 \\
Mexicano & 1 \\
Pardo & 1 \\
Presbíteros (españoles) & 10 \\
Sin identificar & 197 \\
Total & 365
\end{tabular}

Fuente: Núñez, (1845). Memorias de la Sociedad Económica Amigos del País, pp.122-126.

El historiador Cayetano Núñez de Villavicencio no referencia la fuente de este censo, y además se desconocen los factores tenidos en cuenta para lograr tal agrupación de individuos en el caso de los dos primeros apartados. Es probable que en la sección "Naturales" fueran incluidos aquellos nacidos de padre o madre indios, pues de lo contrario hubieran sido incorporados en el primer acápite. Si este fuera el caso, por vez primera se alude al mestizaje en una relación de habitantes de Guanabacoa y se contabilizan los residentes procedentes de otras regiones americanas, con resalte para los cuatro floridanos, aunque no se especifica si son indios o no. El censo expuesto antes difiere de las cifras presentadas por Juan de Texeda solo quince años antes, quien había aseverado que solo había sesenta indios en Guanabacoa; ${ }^{4}$ el 22 de septiembre de 1608 el obispo

4. Archivo General de Indias: Carta de Texeda a S. M., 25 de abril de 1590 .
Fray Juan de las Cabezas y Altamirano afirmaba haber encontrado sesenta vecinos y 300 indios en esta localidad (Macías, 1978), "(...) ques un pueblo de yndios [con no más] de 60 casas de paja” (Macías, 1978, p. 18). Las dos últimas cifras son considerablemente extremas; las diferencias de tales números hacen dudar de su veracidad, aunque el primero pudo haberse referido a los nacidos de padre y madres indios, y el segundo contabilizar también a aquellos identificados como naturales en la tabla antes expuesta.

La descendencia indígena guanabacoense de fines del siglo XvI e inicios del XvII se hallaba integrada a la sociedad colonial insular al desempeñarse como oficiales de milicias, monteros, ceramistas y ganaderos, además de continuar con sus labores en las estancias agrícolas lindantes con las poblaciones. En carta dirigida al Rey, con motivo de una visita pastoral a la Isla en 1620 para supervisar el tratamiento a los naturales, el obispo Alonso Enríquez de Armendáriz refiere que continuaban atropellados por su origen y color de piel. Anota que “(...) en este pueblo de Guanabacoa, que es donde hay más número de indios, padecen muchísimo, porque les han usurpado sus tierras y los han arrinconado, de manera que no tienen donde sembrar" (Pichardo, 1984, p. 574). El informe enviado a la Corona por dicho obispo contenía datos relativos a los habitantes de Cuba, esta vez contabilizados totalmente, en el que reafirmaba que la capital poseía casi 7000 moradores. Según Armendáriz, 170 de ellos residían en Guanabacoa, “(...) la mayor parte (...) descendientes de indios: hay algunos españoles mezclados, pero indios naturales hasta cincuenta" (Pichardo, 1984, p. 568).

La revisión de volúmenes contentivos de datos referentes a los difuntos de Guanabacoa, fechados desde el 23 de enero de 1659 hasta el 22 de diciembre de 1685 , produjo el resultado siguiente: 138 blancos, 22 negros, 7 mulatos, 58 sin especificar, 22 indios naturales (adultos varones 4, adultos hembras 7 , 
niñas 4, niños 6, sin edad especificada 1). ${ }^{5}$ Estas cifras reflejan la pervivencia de la descendencia aborigen a finales del siglo XvII, tomando además en consideración que dentro de los acápites Mulatos y Sin especificar pudieran haberse contemplado a los hijos de las parejas formadas por indios y pobladores negros y blancos.

Con respecto a las relaciones establecidas entre $\mathrm{La}$ Habana y La Florida, puede argüirse que se inician en el año 1513, con la llegada a la península del conquistador español Juan Ponce de León (Romero, 1995, p. 141). A partir de entonces se produjo un trasiego eventual de indios floridanos hacia Cuba, y en el año 1569 Pedro Menéndez de Avilés creó en La Habana lo que pudiera llamarse el primer colegio jesuita interindiano, destinado a educar a niños y jóvenes de la vecina Florida (Marrero, 1976 citado por Jiménez y Arrazcaeta, 2010, p. 7). El investigador Salvador Larrúa (2014) señalaba que entre los siglos XVI y XVIII los floridanos llegaban en canoas a La Habana y desembarcaban en la Plaza de San Francisco de Asís carnes secas, pescados, tortugas, ámbar gris, cerámicas y pieles. Hacia 1580 el fuerte olor del pescado comenzó a molestar a los vecinos, por lo que se les asignó un sitio en el lado opuesto de la bahía para vender estas mercancías. Con el paso del tiempo, algunos indios floridanos situaron allí sus viviendas y así nació el pueblo de Casablanca. ${ }^{6}$ Otros se asentaron en Guanabacoa, donde fundaron familias y progresaron en sus negocios; los testamentos dan fe de que legaron a sus descendientes adornos de oro, piedras preciosas, telas y grandes sumas en monedas de oro y plata. ${ }^{7}$

Entre los ańos 1720 y 1724 existía una comunidad con más de 200 indios floridanos viviendo en los

5. Libro 1 de Difuntos, Libro 2 de Difuntos Pardos y Morenos, Archivo Parroquial de Guanabacoa.

6. Ubicado en las faldas de la loma, en cuya cima se localizó posteriormente la fortaleza San Carlos de La Cabaña.

7. Cf. Registros del Archivo de Protocolos de La Habana, años 1580 y ss. (Larrúa-Guédes, 2014, p. 2) alrededores de La Habana; en Guanabacoa sobrevivía posiblemente un reducido grupo hacia 1731 (Díaz, 1729 y Soto, 1731, en Worth, 2004). De dicha época se ha documentado la presencia de una mujer Calusa cuyo nombre fue Leonor Sayas, bautizada así probablemente en honor de la progenitora o la hermana de don Cristóbal de Sayas Bazán, sacristán de la parroquia de esta villa ultramarina. Este había sido designado por el obispo Jerónimo de Nostris y de Valdés para aprender el idioma de estos inmigrantes y actuar como protector de los "Indios de los cayos de la costa de Florida" (Díaz, 1729 y Soto, 1731, en Worth, 2004, p. 7).

Es conocido que desde las tierras al sur de La Florida arribaron a La Habana indios Calusas entre 1704 y 1711, período durante el cual eran asediados por los guerreros Creek y Yamasee, que los utilizaban como mercancía para el comercio de esclavos con los colonizadores británicos. En la primavera de esta última fecha fueron transportados hacia La Habana 270 Calusas, los que fueron ubicados en las áreas que hoy ocupa la fortaleza San Carlos de La Cabaña, siendo reubicados posteriormente en Guanabacoa (Tamayo, 2004, p. 8).

Tras el ataque de La Habana por los ingleses en 1762 y su devolución en 1763, España cedió a Inglaterra la colonia de La Florida, lo que propició que llegaran a La Habana Timucuanos, Yamasees y Guales cristianizados en las misiones franciscanas del norte de La Florida (Tamayo, 2004, p. 9). Un grupo compuesto por 101 indios fueron reubicados en Guanabacoa, donde vecinos y naturales los acogieron y entrenaron en oficios propios del territorio. ${ }^{8}$ En la región habanera estuvieron representadas diversas etnias floridanas; entre los inicios del siglo Xvi y hasta el año 1823 se reportan miembros de los pueblos Calusa, Timucua, Creek, Jove, Miami, Tancha, Muspa, Rioseco (o Jeaga), Yamasee e indios de Georgia (Worth, 2004, pp. 1,

8. Cabildo del 20 de enero de 1764 (Núńez, 1845, pp. 127-128). 
$5,6,8$ y 9). Una interesante evidencia material de la presencia de los mismos ha sido el hallazgo, en una veintena de sitios arqueológicos habaneros, de vasijas elaboradas en conchas de tres especies de moluscos marinos del género Busycon, lo que indica el alto índice de introducción de estos artefactos desde La Florida.

\section{Primera iglesia y cementerio de Guanabacoa}

En el año 1576 se solicitó al cabildo habanero la construcción de la primera iglesia de Guanabacoa, y gracias a los esfuerzos de un presbítero franciscano y la cooperación de Hernán Manrique de Rojas, protector de indios, el prelado Juan del Castillo aprobaba la obra en abril de 1577 (Vidal, 1887, pp. 19-20). Abierta al culto el 15 de agosto de 1578, se hallaba bajo la advocación de María Santísima de la Asunción (Vidal, 1887, p. 20; Guardia, 1946, p. 22). A partir de entonces, los enterramientos de los fallecidos se efectuaron en el cementerio del santuario, que por sus reducidas dimensiones debió situarse tanto en su interior como en sus alrededores, lo que provocó que la zona se conociera posteriormente como el "Barrio del Campo-Santo" (Núñez, 1845, p. 93).

En 1586, el sacerdote franciscano que oficiaba en la iglesia “(...) recabó de casi todos los indígenas, establecidos en las lomas del Indio y de la Cruz, que trasladasen (...) junto á la Iglesia su morada”, así como de algunas familias canarias (Vidal, 1887, p. 20). En opinión del historiador Elpidio de La Guardia, esto produjo un "(...) acercamiento social entre unos y otros, y lo que es más aún, la unión de las dos razas, al surgir numerosos matrimonios" (1946, p. 23). Sin embargo, el 12 de diciembre del año 1582 se reportaban en Guanabacoa 46 indios naturales, y solo 11 vecinos de origen europeo, censo en el que no constan las féminas ni los infantes (Wright, 1927, p. 313).9 Aunque lógicamente se conformaran parejas compuestas por indios

9. Lista y memoria de los vezinos y moradores desta villa de la havana $y$ del pueblo de guanavacoa. y pobladores "blancos", como afirmaba Guardia, resulta evidente que existían mayores probabilidades de que se efectuaran uniones consensuadas entre pobladores naturales, ya que constituían mayoría abrumadora. Asentados en la mencionada Loma del Ermitańo o Loma del Indio (o de Los Indios), al este de la zona en estudio, constituía una pequeña elevación sobre la que se habían asentado los naturales desde la fundación de la reducción; por lo tanto, esta pequeña colina, junto al poblado de Tarraco, fueron los dos núcleos poblacionales primarios de Guanabacoa.

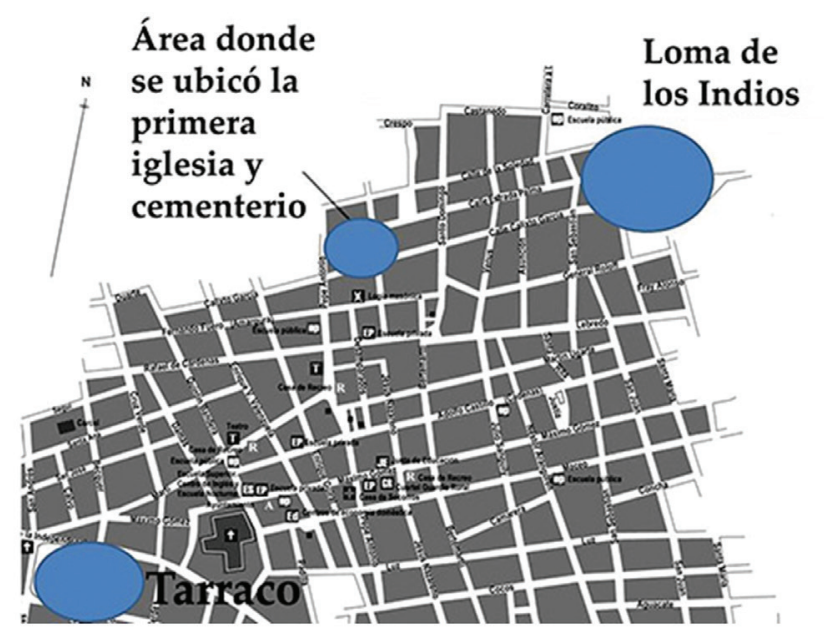

Figura 3. Ubicación de Tarraco, la Loma de los Indios, y la primera iglesia y cementerio de Guanabacoa.

Fuente: plano confeccionado por Lisette Roura.

Habiéndosele otorgado la categoría de Iglesia Parroquial el 15 de agosto de 1607 (Guardia, 1946, p. 77), Fray Alonso Enríquez de Almendáriz relataba en 1620 que esta antigua edificación poseía techo de tejas y contaba con los servicios del cura Francisco de Viera, natural de La Habana, de más de 40 años. $^{10}$ (Pichardo, 1984, p. 574) En 1665 "(...) aparece representado como un sencillo edificio de planta rectangular con tejado a dos aguas (...), y en lo alto de la fachada, sobre el caballete, se

10. Visita pastoral del obispo Fray Alonso Enríquez de Almendáriz, carta del 12 de agosto de 1620. 
hallaba colocada una cruz" (Rodríguez, 2007, p. 11). Cuando en el año 1721 se termina de construir la "nueva" Iglesia Parroquial de la localidad, se derriba el antiguo edificio por su estado ruinoso y se coloca en su lugar una cruz de madera.

Retirada la señalización en el año 1820, por disposición del obispo Juan José Díaz de Espada y Fernández de Landa (Vidal, 1887, p. 20), el área paulatinamente fue ocupada por viviendas. La diversidad de opiniones en cuanto a la ubicación de la primera iglesia y cementerio de la localidad confirma la necesidad de comprobar la localización de ambos, pues esta área constituye el núcleo a partir del cual el poblado de Guanabacoa se expande y de forma paulatina toma su configuración definitiva.

\section{Intervenciones arqueológicas}

La localización y el estudio de las tres áreas de ocupación humana más antiguas de Guanabacoa resultan de vital importancia para la historia local y regional. Las investigaciones histórico-arqueológicas en el área urbana de este municipio comienzan en el año 1970, fecha en que se deposita en los almacenes del otrora Centro de Antropología, perteneciente a la Academia de Ciencias de Cuba, una vasija acordelada ${ }^{11}$ con dos asas, procedente del Convento San Francisco de Asís, más conocido como Colegio de Los Escolapios. (Aida Martínez, comunicación personal, 2014). Aunque se desconozca la procedencia de este contenedor, lo cierto es que destaca por su excelente estado de conservación, y pueden observarse huellas de reparación y uso continuado; además, su forma recuerda ciertas vasijas halladas en sitios indígenas del Caribe (Jorge Ulloa Hung, comunicación personal, 2015). Cinco años más tarde, de manera fortuita, se exhuma un fragmento cerámico atribuible a los naturales

11. El acordelado (coiling, enrolletado) y el modelado fueron las técnicas utilizadas por las comunidades apropiadoras tardías y productoras, en el archipiélago cubano, para efectuar el levantado de los ceramios. que vivieron en el área conocida como Tarraco (Pérez y Macías, 1991, p. 1); este sitio arqueológico fue nombrado Guanabacoa I. En los meses de mayo y junio de 1987, la arqueóloga Lourdes $S$. Domínguez dirige investigaciones arqueológicas en otros dos sitios: Guanabacoa 2 (antigua Loma de los Indios) y Guanabacoa 3 (zona conocida como Tarraco), en busca de evidencias arqueológicas pertenecientes a los dos antiguos asentamientos.

La tercera excavación, practicada también en el área conocida como Tarraco, fue catalogada como Guanabacoa 4. En las tres excavaciones se extrajeron numerosas evidencias; en todos los casos, la profundidad máxima fue de $1,00 \mathrm{~m}$, y se exhumaron 14656 fragmentos, correspondientes a gran variedad de grupos y tipologías (Domínguez, 2004, p. 5). Las investigaciones se enfocaron en el rescate de artefactos que denotaran la ubicación de los mencionados poblados, por tanto, quedaría por dilucidar dónde se encontraban la primera iglesia y cementerio de la localidad, ya que el hallazgo y el análisis de las evidencias arqueológicas, y de los procesos de formación del contexto arqueológico en el área en estudio contribuirían a la reformulación de aspectos relacionados con la descendencia biológica y cultural aborigen en Guanabacoa, la continuidad de actividades vinculadas con producciones de tradiciones aruacas, la presencia de indios floridanos en el entorno urbano y la incidencia de rasgos identitarios de ambos grupos en la conformación del pueblo-villa-municipio.

El proyecto arqueológico comenzó a ejecutarse en coordinación y con representación del Museo Municipal del territorio. Se diseñó teniendo en cuenta la disponibilidad de patios o solares sin edificaciones, y el apoyo de los propietarios de los mismos para ejecutar las excavaciones. En el área se identificaron dos patios como los espacios con mejores condiciones para efectuar las investigaciones, y además con gran potencialidad en cuanto al hallazgo de evidencias relacionadas con los objetivos del proyecto, teniendo en cuenta la ubicación de ambos. 


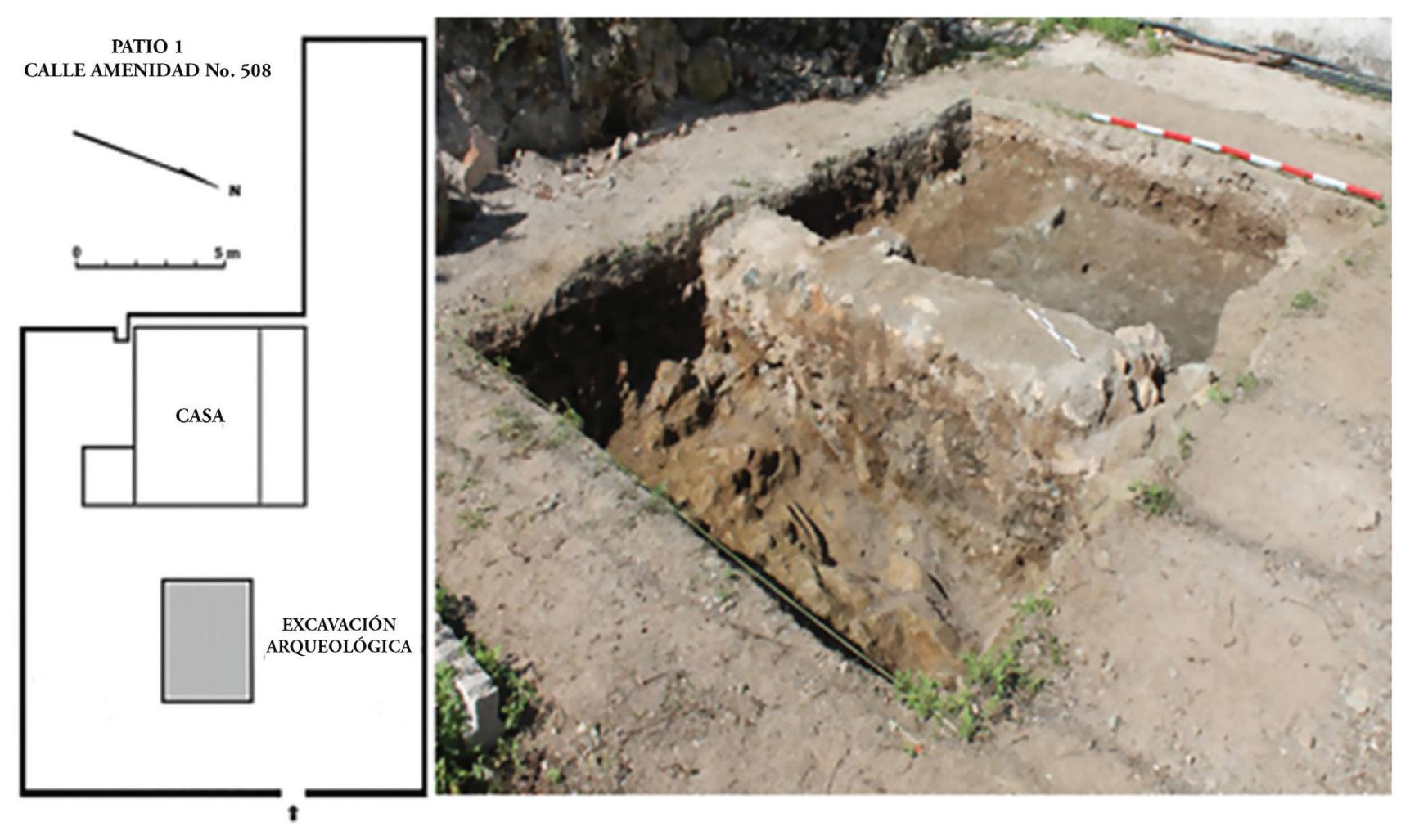

Figura 4. Plano que muestra la ubicación de la excavación arqueológica en el patio intervenido y vista general de la misma.

Fuente: plano y fotografía de Lisette Roura.

El desnivel del terreno que puede observarse entre el patio intervenido y la calle pudiera sugerir posibles labores de rellenado en toda la zona, uno de los argumentos que justificaba la inexistencia de excavaciones en dicho sitio. Sin embargo, la observación de los patios colindantes y la disposición de las fachadas de las casas apuntan hacia la eliminación de los desniveles en la falda de una pequeña elevación, con el objetivo de situar paulatinamente los inmuebles, lo que corrobora la tesis sobre la ubicación de la primera iglesia en las inmediaciones de una pequeña colina. Se situó un área de excavación de $4 \mathrm{~m} \times 3 \mathrm{~m}$, teniendo en cuenta la posición del camino de acceso a la vivienda del propietario del solar y eludiendo una zona con grandes concentraciones de rocas producidas por el derrumbe de una edificación existente en el siglo XIx. La superficie presentó huellas de surcos para sembrados, y una vez retirada esta unidad estratigráfica comenzaron a aflorar restos de muros de mampuesto y contextos pertenecientes al siglo XIX. Estos a su vez fueron colocados tras practicar cortes en las unidades correspondientes con el siglo XVIII, entre las que se encontraba un apisonado de cal, vestigio del primer pavimento e inmueble colocado en el área.

En total se identificaron 16 unidades estratigráficas y la profundidad máxima de la excavación fue $0,90 \mathrm{~m}$, develando el afloramiento de serpentinita, roca ofiolítica que constituye el lecho natural de gran parte del territorio guanabacoense. A pesar de que no constituyó una intervención de gran profundidad, los contextos excavados resultaron ser muy fértiles en artefactos, con una estratificación que permite determinar acciones antrópicas significativas. Mediante el análisis de la disposición de los estratos y las evidencias se reconocieron tres periodos cronológicos diferentes. Un primer momento de 
ocupación en el siglo XviII, para lo cual se necesitó rellenar y nivelar el terreno, utilizando material terrígeno de diversa procedencia. Este lapso cronológico está sellado por un apisonado de cal, lo que indica la probable ubicación de un primer inmueble en el área. Posteriormente, dicho apisonado fue cortado por un muro que perteneciera a un inmueble construido durante el siglo xIx, al cual también corresponde otro apisonado de cal. Por último, el deterioro de la edificación decimonónica en el siglo Xx condicionó que la zona se cubriera paulatinamente por sedimentos varios, situación que fue aprovechada por el propietario de la parcela para situar algunos sembrados.

Las unidades estratigráficas constituyen, en su mayoría, contextos secundarios, y la naturaleza de las mismas indica su origen doméstico o un posible acarreo desde zonas de basurero, debido al alto grado de fragmentación de los artefactos, gran cantidad de restos bioarqueológicos con huellas de cortes (sobre todo en huesos pertenecientes a mamíferos), y en el caso de las especies comestibles la preponderancia de las porciones que solían comercializarse. Se han identificado fragmentos pertenecientes a moluscos marinos: ostión de mangle (Crassostrea rhizophorae), baya (Isognomon alatus), Codakia orbicularis, Tellina sp., Arca sp., Chione cancellata, Mytilopsis leucophaeata, sigua (Cittarium pica), cobo (Lobatus gigas), Bulla striata y un fragmento pequeño de Sinistrofulgur perversum. Los moluscos terrestres están representados por el Cerion sp. y la Zachrysia auricoma, mientras que se identificaron vértebras y otros restos de peces como el aguají (Mycteroperca bonaci), la jiguagua (Caranx hippos) y el pargo criollo (Lutjanus analis). Igualmente, se exhumaron restos de jicotea (Trachemys decussata), gallina (Gallus gallus), perro (Canis familiaris), cerdo (Sus scrofa), vaca (Bos taurus), conejo (Oryctolagus cuniculus) y de Ovis/Capra. ${ }^{12}$

12. El estudio de los restos bioarqueológicos fue realizado por Osvaldo Jiménez Vázquez, especialista del Gabinete de Arqueología de la Oficina del Historiador de La Habana.
Entre las evidencias más significativas puede mencionarse una vasija confeccionada a partir de un ejemplar del molusco marino Sinistrofulgur perversum, ${ }^{13}$ usualmente conocido como Busycon perversum. Estos gasterópodos habitan desde Carolina del Norte, Estados Unidos, hasta la península de Yucatán, México, ${ }^{14}$ por lo que es muy significativo que se exhumen en contextos arqueológicos cubanos. La pieza hallada probablemente fuera desechada tras fracturarse la porción superior de la concha y parte del manto. Para lograr la hechura del artefacto se extrajo la columela y parte del labio interno, y tanto el labio externo como el interno fueron rebajados, posiblemente con el objetivo de no dañar la boca y propiciar un mejor agarre respectivamente. Aunque este ejemplar no posee pulimentado en la superficie dorsal, puede observarse cierto desgaste en la zona más cercana al canal sifonal, precisamente por donde la vasija debía sostenerse y manipularse, lo que indica su reiterada utilización.

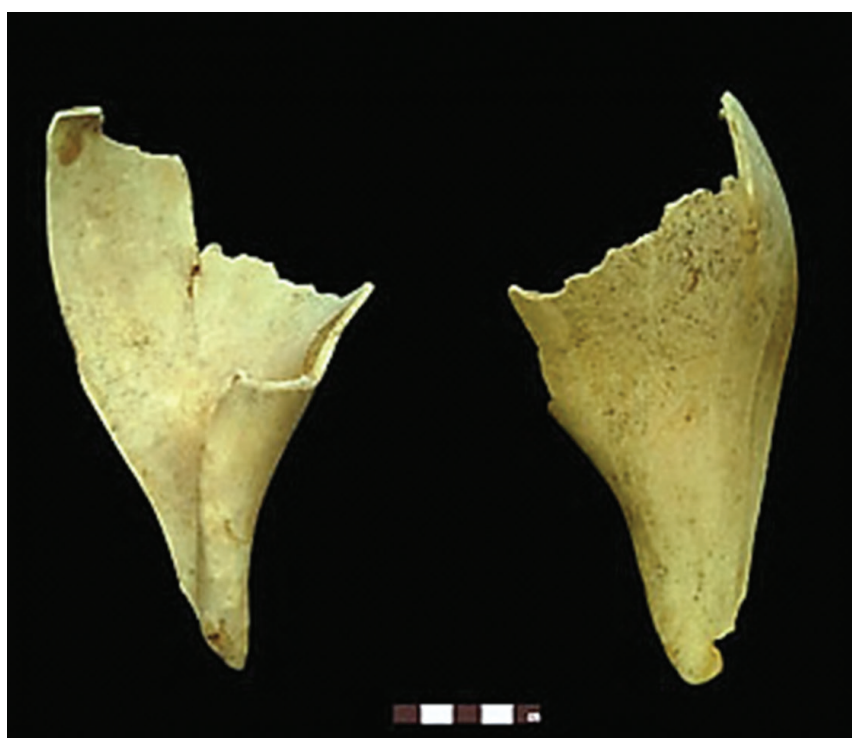

Figura 5. Vasija confeccionada con el manto del molusco marino Sinistrofulgur perversum.

Fuente: fotografías de Lisette Roura.

13. World Register of Marine Species. Recuperado de http://www. marinespecies.org

14. Busycon perversum. Recuperado de http://www.gastropods. com/9/Shell_349.shtml 
Con respecto a las vasijas de la familia Busyconidae halladas en La Habana, el arqueólogo Leandro Romero (1995) apuntaba que dichos artefactos se habían utilizado como achicadores durante las travesías en canoas desde La Florida (Jiménez y Arrazcaeta, 2010, p. 4). Sin embargo, tres de los más de veinte ejemplares encontrados muestran un pulimento dorsal excepcional. "Estos recipientes parecen ser copas ceremoniales empleadas en el consumo de la bebida negra, casseena o casina para los españoles, (...) que se obtenía hirviendo las hojas del Yaupon Holly -Ilex vomitoria-, planta (...) común en el sudeste de los Estados Unidos" (Jiménez y Arrazcaeta, 2010, p. 4). Con excepción de los posibles recipientes ceremoniales antes mencionados, los restantes constituyen vasijas de uso común, muy similares tipológicamente a los cucharones/vasijas estudiados por W. H. Marquardt en 1992 (Jiménez y Arrazcaeta, 2010, p. 7). Lo cierto es que estos artefactos pudieran haberse utilizado como achicadores durante las travesías y como vasijas una vez que sus portadores llegaban a sus destinos, lo que constituye evidencias de las relaciones existentes entre La Florida y La Habana. El ejemplar descrito se halló compartiendo contexto con evidencias datadas en el XVIII, siglo en que se asentaron numerosos indios floridanos en Guanabacoa.

Singular resulta el hallazgo de un sello de plomo con una capa fina de oro en el anverso (el reverso es liso), el engarce de la cinta partido y en estado de conservación regular. Representa el Escudo de Armas del monarca británico, dividido en cuatro cuarteles rodeados por el lema Honni soit qui maly pense (en francés antiguo: Maldito sea el malpensado), aludiendo a la Nobilísima Orden de la Jarretera, orden de caballería más relevante y antigua del Reino Unido, fundada en 1348 por el rey Eduardo III.
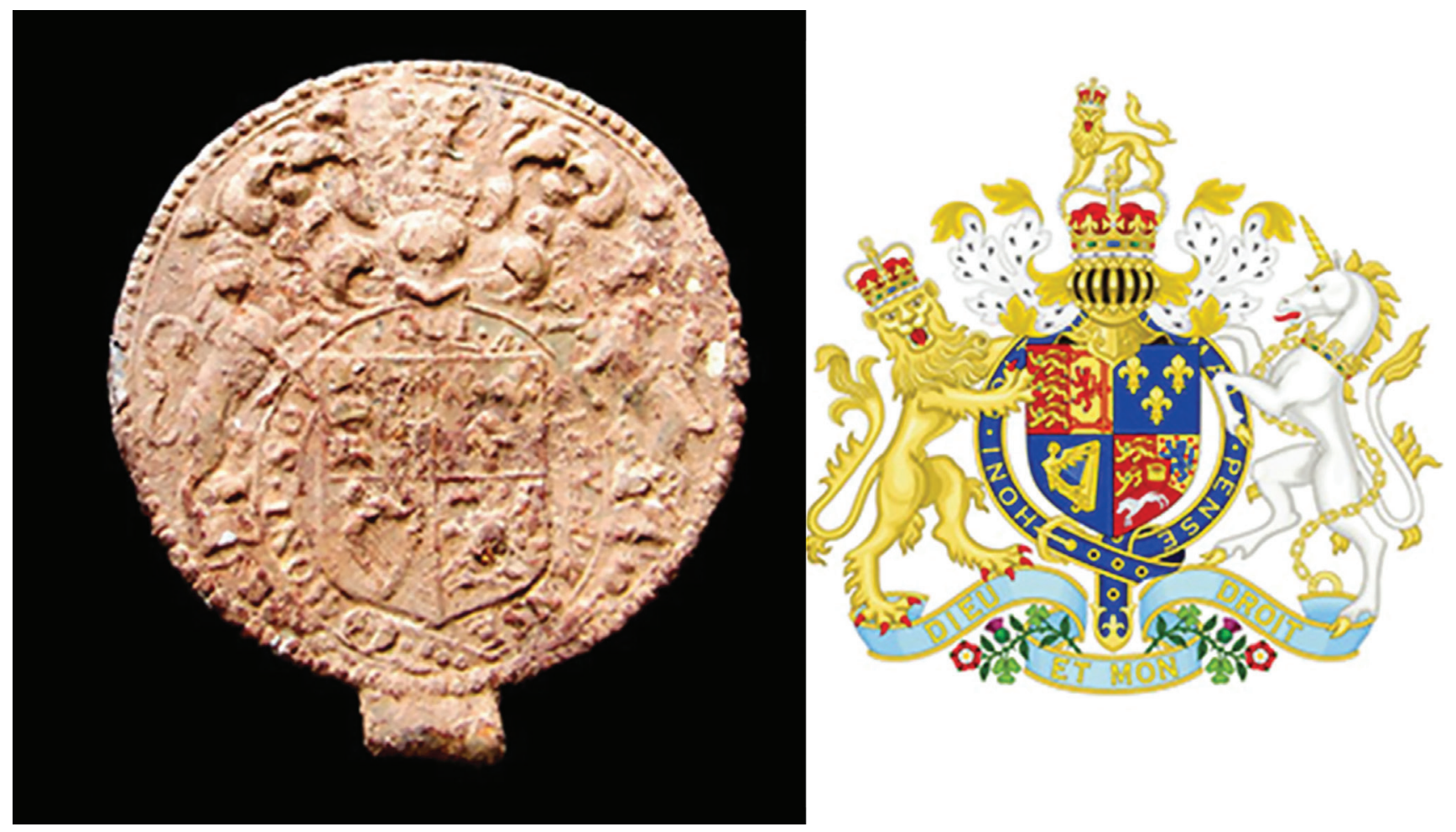

Figura 6. Sello británico hallado y reconstrucción de la figura que muestra el anverso.

Fuente: fotografía de Lisette Roura. y dibujo tomado de https://es.wikipedia.org/wiki/Escudo_del_Reino_Unido 
Constituye un sello pendiente de cinta confeccionado en el Reino Unido, utilizado entre los años 1714 y 1801 con la finalidad de fedatear ${ }^{15}$ documentos de diversa índole. ${ }^{16} \mathrm{Si}$ se toma en cuenta la naturaleza del contexto en que se halló este artefacto y el rango cronológico en que se empleó, bien pudo guardar relación con la Toma de La Habana por los ingleses en 1762. Como consecuencia de la invasión británica, Guanabacoa padeció grandes afectaciones: sufrió una significativa despoblación ante la inminente batalla, y el saqueo de templos católicos y moradas, así como la quema de algunas casas (Rodríguez et al., 2006, p. 91). Es posible entonces que el sello se desechara o pasara a formar parte de un contexto primario como elemento de facto, consecuencia quizás del intenso trasiego de soldados y civiles británicos. Con posterioridad, dicho contexto se trasladó hacia el sitio en estudio durante el siglo XviII, conclusión a la que se arriba tras el análisis de las relaciones cronológicas y espaciales artefactuales, e intercontextuales.

Algunas otras evidencias merecen mencionarse, como un dado de hueso, un abanico calado de hueso, una pequeña figurilla de cerámica que recuerda una imagen religiosa, dos fragmentos de pipas de caolín para fumar tabaco, hormillas de hueso, una cuenta de roca para collar, tejas criollas (acanaladas o de muslo), fragmentos de ladrillos y losas de piso. Debido al significativo desarrollo de la industria azucarera en territorio guanabacoense (Rodríguez et al., 2006, pp. 51-53) se elaboró gran cantidad de cerámica para tales fines, lo que justifica el hallazgo de fragmentos de cuerpos, bordes y furos de hormas utilizadas en el proceso de obtención del azúcar, todos con restos de cal.

15. Autenticar o dar fe pública de documentos, acción que efectuaban fedatarios o notarios.

16. Para realizar la descripción y datación del sello, se contó con la colaboración del especialista en numismática Israel Corrales Vázquez, y se consultaron los sitios web: http://www.buscadores-tesoros.com/t18468-sellos-siglo-xviii, y https://es.wikipedia. org/wiki/Escudo_del_Reino_Unido
Dentro del conjunto de evidencias halladas destacan, por su cantidad y características, las fichas de juego. De las ocho exhumadas, tres se desecharon en pleno proceso de factura, en seis se reutilizaron fragmentos de vasijas de cerámica de tradición aborigen de diferentes grosores, y en los otros dos casos se aprovecharon fragmentos de mayólica, una clasificada como Talavera azul sobre blanco (15901750). Algunas similares se han identificado en contextos de los siglos XVI y XVII, correspondientes con la antigua ferretería Isasi, de La Habana Vieja. En opinión del arqueólogo Daniel Schávelzon (2010), las fichas pueden identificarse como:

(...) trebejos usados en dos juegos que fueron habituales en las colonias españolas y en España denominados chaquete o tablas reales, y damas. Ambos juegos han llegado la actualidad siendo el chaquete el llamado Backgammon en su denominación inglesa y las Damas aún mantienen su nombre en la América hispánica. Se practican sobre tableros aunque suponemos que también debieron hacerse directamente sobre marcas en el piso y a este último caso deben pertenecer las fichas de mayor tamaño (p. 3).

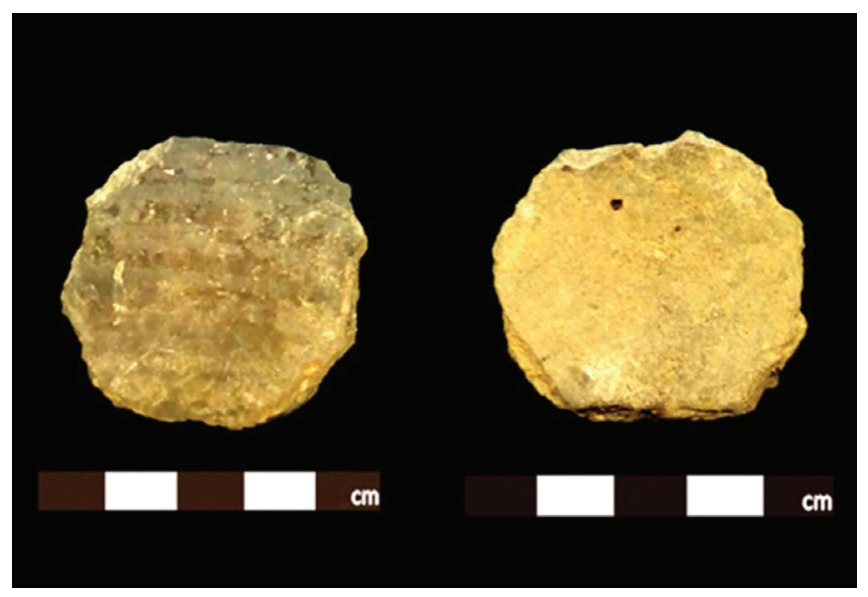

Figura 7. Fichas de juego facturadas en fragmentos de cerámica de tradición aborigen.

Fuente: fotografías de Lisette Roura. 
Los investigadores Lydia Pulsipher y Conrad Goodwin describen un juego moderno en la isla de Montserrat al que llaman Chiney Money, en el que se emplean tres discos de cerámica similares a los encontrados en sitios arqueológicos (Singleton, 2005, p. 12), mientras que Kathleen Deagan agrega el parchís como otro posible juego de azar donde podían utilizarse las fichas de cerámica (Deagan, 2002, p. 232). Es muy significativo que para el caso que nos ocupa, la mayor parte de estas evidencias se confeccionaran a partir de cerámica acordelada de tradición aborigen, teniendo en cuenta que la mayoría de las encontradas en Cuba solían elaborarse con fragmentería de mayólicas y, durante el siglo XIX, con lozas finas. Algunos autores, como Hernández (2012), asumen que la factura y utilización de las mismas podían ser llevadas a cabo por grupos sociales poco favorecidos, como esclavos, soldados e indios.

Muy interesante resulta el fragmento de vasija de cerámica de tradición aborigen (siglo XviII) que presenta decoración incisa en el borde. Aunque las incisiones difieren de las encontradas en contextos del siglo Xvi en La Habana Vieja, constituye el borde inciso más tardío hallado hasta el momento en el territorio habanero. Los bordes identificados en los ejemplares exhumados son redondeados, con excepción de uno evertido, constituyendo mayoría los tiestos de cerámica de tradición aborigen en los contextos correspondientes con el siglo XVIII, mientras que su número desciende considerablemente en los estratos del siglo XIX.

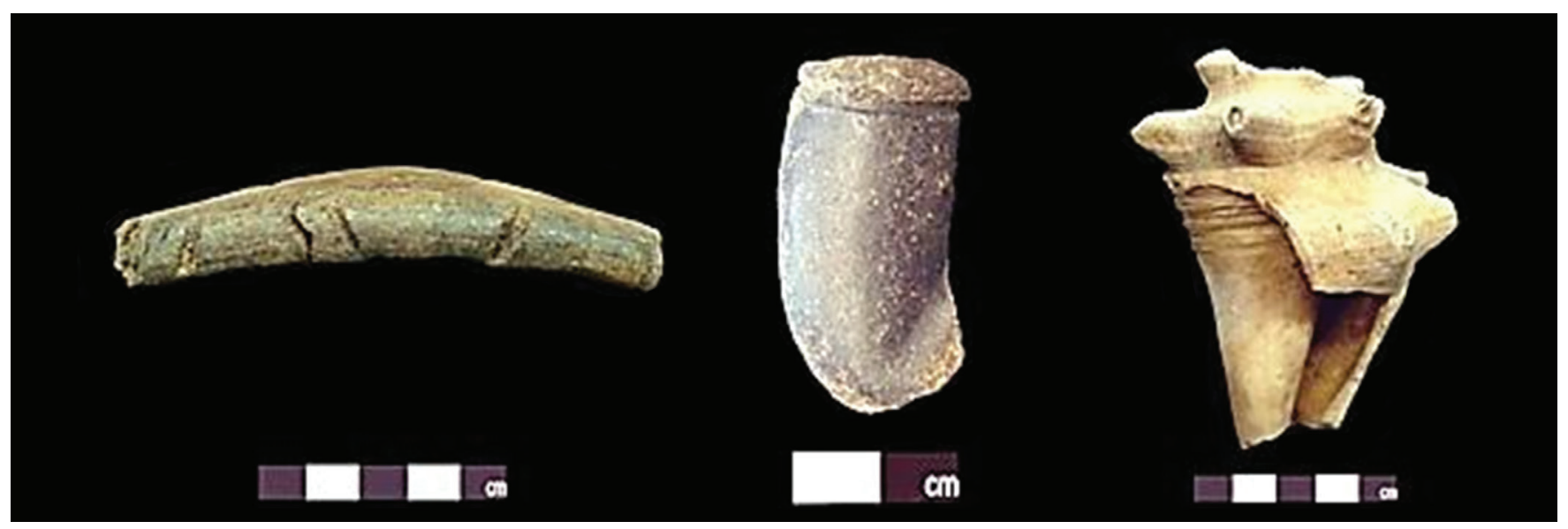

Figura 8. De izquierda a derecha, fragmento de cerámica de tradición aborigen con el borde inciso, fragmento de pipa de cerámica negra para fumar tabaco, y pico de mano facturado con la concha del molusco Strombus pugilis.

Fuente: fotografías de Lisette Roura.

Se exhumó además un pico de mano confeccionado en un ejemplar de Strombus pugilis, con la parte inferior fracturada, al que le fue retirado parte del manto y el ápice para facilitar el agarre y la percusión. Tres fragmentos de burenes, uno con borde, confirman la consecución de la producción de casabe, ya fuera para el consumo familiar o para su comercialización. Muy gratificante resultó hallar una porción de cánula de una pipa de cerámica ordinaria negra; ejemplares similares encontrados en La Habana Vieja se han atribuido a la descendencia aborigen en la región, pues constituyen ejemplares de factura artesanal con acabado muy rudimentario (Roger Arrazcaeta, comunicación personal, 2019), y el caso que nos ocupa presenta una línea incisa que rodea la boquilla. 
La presencia de cerámica de tradición aborigen, el pico de mano, así como los fragmentos de burenes y la porción de pipa, alude a la continuidad histórica de la representación en la materialidad de rasgos identitarios autóctonos, al menos hasta el siglo XVIII, elementos culturales que persistieron y se transocializaron como componentes de un grupo social oprimido, sometido y condenado a expresiones de marginalidad social. El reajuste de las estrategias de investigación mediante la superación del manejo aislado de evidencias llamadas "de transculturación", y además el reconocimiento de la importancia del conjunto artefactual partiendo del dinamismo que caracteriza la formación de los contextos arqueológicos urbanos, sugieren que el comportamiento de la descendencia indígena ante la dinámica social impuesta por las autoridades coloniales condicionó la continuidad manufacturera de artefactos utilitarios relacionados fundamentalmente con actividades vinculadas a la elaboración de alimentos, la producción de casabe y a la tradición de fumar tabaco. En otros casos, como los juegos de azar, constituyeron prácticas adquiridas durante el tránsito de los naturales por procesos sociohistóricos durante la época colonial. Progresivamente la arqueología va contribuyendo a la visibilizando del indio de diferentes orígenes y en diferentes momentos de la historia de la región habanera, repensando la manera en que se ha tratado su temprana desaparición y llenando el vacío que por muchos años legitimó la historiografía.

\section{Consideraciones finales}

A pesar de que no fue posible localizar evidencias de la primera iglesia y cementerio de Guanabacoa en el sitio elegido para la primera etapa del proyecto, se rescataron relevantes artefactos que permiten ahondar en cuestiones relativas a los habitantes del territorio. Los resultados de la intervención arqueológica descartan esta área como asentamiento del antiguo templo y camposanto, y comprobaron la ocupación continuada del espacio a partir del siglo XVIII.
Si se tiene en cuenta, que debido a los conflictos políticos existentes entre España y el Reino Unido es muy poco probable que un sello como el encontrado fuera introducido en el país y pasara a formar parte del registro arqueológico con anterioridad al año 1762, puede argüirse entonces que tanto la formación de los contextos utilizados para nivelar como las acciones de rellenado se efectuaron durante los últimos cuarenta años del siglo XvıII, tesis sustentada por la ausencia de evidencias correspondientes con el siglo XIX en los estratos sobre los que se situó el pavimento del primer inmueble construido en el área. Los artefactos colectados se vinculan con actividades relacionadas con la cotidianidad de los habitantes guanabacoenses, desarrolladas tanto dentro como fuera de las viviendas, tales como el comercio, la producción de azúcar, la práctica religiosa, el divertimento, la construcción, la alimentación, el procesamiento de alimentos y aquellas que incluían elementos vinculados con la apariencia personal.

Aun cuando los contextos arqueológicos exhumados fueron identificados como secundarios y no fue posible localizar el cementerio y el ajuar artefactual asociado a los enterramientos humanos, la presencia de la vasija confeccionada con la concha del molusco marino Sinistrofulgur perversum y otro fragmento de la misma especie corrobora arqueológicamente por vez primera la presencia en Guanabacoa de sujetos procedentes de La Florida, asentados en una región donde aún habitaban aquellos individuos que confeccionaban artefactos con técnicas y materiales tradicionales autóctonos.

Afortunadamente, la ejecución de este proyecto propiciará el montaje de una sala dedicada a la evolución del territorio como pueblo de indios, pues la insuficiencia de artefactos limitaba el diseño de una exposición con esta temática. La implementación de futuras intervenciones arqueológicas permitirá ahondar en la conformación y cotidianidad de la población guanabacoense, y en la distribución espacial de los inmuebles situados en al menos esta porción del poblado-villa-municipio desde 
el siglo XvI, relevantes aspectos de la historia local $\mathrm{y}$ regional.

\section{Agradecimientos}

Agradecemos infinitamente a todos los colegas y amigos que participaron en la primera campaña de excavación. A Robert S. Carr, director ejecutivo de Archaeological and Historical Conservancy, Inc.; sin su entusiasmo y colaboración este proyecto no hubiera fructificado. Al Museo Municipal de Guanabacoa, principalmente a su directora Lourdes Millet. A Elvis A. Pérez, por facilitarnos la búsqueda documental. Queremos agradecer especialmente a Arsenio Márquez, propietario del patio intervenido; sin su ayuda y buena voluntad no se hubiera podido emprender este proyecto.

\section{Referencias}

Archivo Histórico de la Oficina del Historiador de La Habana. Actas Capitulares del Ayuntamiento de La Habana trasuntadas (1566-1574). (1939), Vol. II.

Archivo General de Indias. (1567). Plano de La Habana en perspectiva. Mapas y Planos.

Archivo General de Indias. (1590). Carta de Texeda a S. M. Santo Domingo.

Archivo Histórico de Guanabacoa. (1991). Pérez, J. y Macías, Y. Investigación sobre comunidades aborígenes en Guanabacoa.

Archivo Parroquial de Guanabacoa. (1659-1685). Libros de Difuntos Pardos y Morenos.

Deagan, K. A. (2002). Artifacts of the Spanish Colonies of Florida and the Caribbean. 1500-1800. Vol. II. Washington D.C.: Smithsonian Institution Press.

Domínguez, L. S. (2004). Guanabacoa: una experiencia india en nuestra colonización. Gabinete de Arqueología, 3(3), 4-11.

Escudo del Reino Unido. (2011). Recuperado de https://es.wikipedia.org/wiki/Escudo_del_ Reino_Unido Guardia, E. (1946). Historia de Guanabacoa. La Habana, Cuba: Imprenta Noticias.
Hernández, I. (2011). Estudio sobre las comunidades ceramistas en la región habanera. Tesis de Maestría. La Habana, Cuba: Instituto de Historia de Cuba, 2011.

Hernández, O. (2012). Hallazgos arqueológicos en la Casa de Liniers: una ficha de juego fabricada en un plato de mayólica. Recuperado de http:// www.iaa.fadu.uba.ar/cau/?p=3492

Jiménez, O. y Arrazcaeta, R. (2010). Evidencias de aborígenes de La Florida en La Habana: siglos XVII y XVIII. Gabinete de Arqueología, 8(8), 4-14.

Larrúa-Guédes, S. (2014). Floridanos en Cuba, hispano-cubanosen LaFlorida. Recuperadodehttp:// www.elmonarquico.com/texto-diario/mostrar/ 416365/floridanoscuba-hispano-cubanos-florida

The London magazine, or, Gentleman's monthly intelligencer. (1762). Recuperado de https:// babel.hathitrust.org/cgi/pt?id=nyp.33433081 $682555 \&$ view $=1$ up\&seq $=7$

Macías, I. (1978). Cuba en la primera mitad del siglo XVII. Sevilla, Espańa: Consejo Superior de Investigaciones Científicas.

Núñez, C. (1845). Noticias históricas de la Villa de la Asunción de Guanabacoa. Memorias de la Sociedad Económica Amigos del Pais, 116, 122-126.

Pichardo, H. (1984). Documentos para la historia de Cuba. Tomo I. Ciudad de La Habana: Pueblo y Educación.

Portuondo, F. (1965). Historia de Cuba 1492-1898. La Habana, Cuba: Pueblo y Educación.

Rodríguez, M. A. (2002). Indios al este de La Habana. La Habana, Cuba: Extramuros.

Rodríguez, M. A. (2007). Metamorfosis de un edificio colonial. Arquitectura y Urbanismo, XXVIII(1), 9-16.

Rodríguez, M. A., Martínez, X., González, B., Soroa, A. G. y Roque, O. (2006). Historia de Guanabacoa. Ciudad de La Habana. La identidad de la provincia y sus municipios. La Habana, Cuba: Gobierno Provincia La Habana. 
Roig, E. (1963). La Habana. Apuntes históricos. La Habana, Cuba: Consejo Nacional de Cultura.

Romero, L. (1995). La Habana arqueológica y otros ensayos. La Habana, Cuba: Letras Cubanas.

Roura, L. (2014). Acercamiento a los procesos sociohistóricos vinculados con la descendencia aborigen en La Habana colonial. Boletin del Archivo Nacional de Cuba, 22, 132-144.

Roura, L., Arrazcaeta, R. y Hernández, C. A. (2017). Indios de La Habana: aproximación histórica arqueológica. La Habana, Cuba: Ciencias Sociales.

Roura, L. (2018). Continuidad histórica de la descendencia aborigen en La Habana y Guanabacoa hasta 1750 (tesis doctoral). Universidad de La Habana, La Habana, Cuba.

Schávelzon, D. (2010). Las fichas de juego en la arqueología histórica argentina. Recuperado de http:// www.danielschavelzon.com.ar/?p=2927

Sellos siglo XVIII. (2014). Recuperado de http://www. buscadores-tesoros.com/t18468-sellos-siglo-xviii Singleton, T. A. (2005). Investigando la vida del esclavo en el cafetal El Padre. Gabinete de Arqueología, IV(4), 4-13.
Tamayo, R. (2004). El último de Los Calusas. Juventud Rebelde. 27 de junio, pp. 8-9.

Venegas, C. (2012). Ciudad del Nuevo Mundo. La Habana, Cuba: Instituto Cubano de Investigación Cultural Juan Marinello.

Vidal, F. (1887). Historia de la Villa de Guanabacoa. Desde la colonización de Cuba por los españoles hasta nuestros días. La Habana, Cuba: Imprenta La Universal.

Worth, J. E. (2004). A History of Southeastern Indians in Cuba, 1513-1823. 61 $1^{\text {st. Annual }}$ Meeting of the Southeastern Archaeological Conference, University of St. Louis, Missouri, USA.

World Register of Marine Species. (2019). Busycon perversum. Recuperado de http://www.marinespecies.org/aphia.php?p=taxdetails\&id $=747338$

Wright, I. (1927). Historia documentada de San Cristóbal de La Habana en el siglo XVI. Tomo I. La Habana: Imprenta El Siglo xx.

\section{Datos de filiación}

Lisette Roura Alvarez. Arqueóloga, licenciada en Estudios Socioculturales, diplomada en Antropología y Patrimonio, doctora en Ciencias Históricas y Profesora de la Universidad de La Habana. Lidera la Sección de Arqueología del Gabinete de Arqueología de la Oficina del Historiador de La Habana, Cuba. Es autora de monografías y artículos en el ámbito nacional e internacional. Ha definido la Arqueología Industrial y la Interacción Indohispánica en La Habana como líneas fundamentales de trabajo, dirigiendo proyectos relacionados con estos temas. Forma parte del Consejo Científico de la revista Gabinete de Arqueología.

Correo-e: roura@patrimonio.ohc.cu,roura144@gmail.com

Odlanyer Hernández de Lara. Arqueólogo, licenciado en Antropología. Es editor de la revista y sitio web Cuba Arqueológica. Actualmente se desempeña como director de proyectos de campo en Archaeological and Historical Conservancy Inc., USA. Ha sido autor, editor y compilador de varios libros. Desarrolla proyectos de investigación en Arqueología Histórica y Patrimonio Cultural, especialmente Arqueología Urbana, fortificaciones y campos de batalla. Correo-e: hernandezdelara@gmail.com 